\title{
LA ENTREVISTA CLÍNICA COMO INTERVENCIÓN CULTURAL
}

\author{
Emilio González Fernández \\ Servicio Gallego de Salud
}

\section{Resumen.}

El texto contrasta dos formas de establecer la relación médico-paciente: la entrevista protocolizada y fija que utiliza la Medicina hegemónica y la entrevista cultural y cambiante que se va construyendo teniendo en cuenta el Pathos vital de quien hace la demanda médica. Únicamente esta segunda forma hace posible una medicina humanizante.

Palabras clave: Psiquiatría comunitaria, Cultura y medicina, Atractores semánticos, Metáforas, Entrevista clínica y cultura.

\section{Abstract.}

The text contrasts two ways to establish the doctor-patient relationship: interview fixed and protocolized utilized by hegemonic Medicine and cultural and changing interview that is constructed taking into account the vital Pathos by people who makes medical demand and their healers. Only this second form enables a humanizing medicine.

Keywords: Community psychiatry, Culture and medicine, Semantic attractors, Metaphors, Clinical interview and culture.

\section{INTRODUCCIÓN}

Por el inmenso poder de la cirugía en la asistencia sanitaria, tomo la metáfora de la intervención quirúrgica. Puede ser esta más o menos cruenta, pero siempre la considera el usuario como algo especial, que mete respeto o miedo. Pueden devenir accidentes, complicaciones, hallazgos no esperados... 
A menudo el médico olvida que una entrevista clínica también es una intervención cultural. Intervenimos, desde nuestra posición de poder y de modelo médico hegemónico, con poca o mucha agresividad, en la cultura del paciente o del usuario.

Me voy referir a lo que practico: a la entrevista psiquiátrica. Esto no quiere decir que en buena parte sea aplicable a las entrevistas clínicas de todos los profesionales sanitarios. Surgen resistencias cuando se intenta explicar esto a los médicos, a la mayoría de los psiquiatras y psicólogos.

Cuando esto escribo (desmoronamiento del "Estado de medioestar") puede parecer ridículo plantearse estos aspectos. En absoluto. Se alerta en medios "progres" de la necesidad de implementar la participación de los usuarios para salvar el sistema sanitario. Consideran los conspicuos aspirantes a gestores que la participación del usuario se ha de limitar a la presencia de las asociaciones en todos los niveles. Sin embargo, olvidan que esa participación, esa negociación de significados y conductas, atañe y comienza ya en las simples consultas.

En realidad debía comenzar ya antes. Cuando se confecciona el modelo de historia clínica (sea en soporte digital o en papel). El instrumento con el que recogemos síntomas, signos, conductas, quejas, lenguaje de malestar en general, está diseñado por los médicos sin que participen los usuarios. De ahí, que los siguientes pasos (diagnóstico y tratamiento) puedan estar ya "ligeramente" viciados...

Voy a presentarles algunos casos y cosas de mi ya dilatada experiencia profesional en el campo de la salud mental.

\section{DESCENDER MIRANDO (MIRADAS DESCENDENTES)}

Aunque no puedo ubicarlo en un tiempo concreto, en mi práctica clínica ha existido un virtual "rito de paso" que alcanza para mi novela biográfica categoría de evento trascendente. Sí que estoy seguro que se ha producido en el espacio sanitario de una consulta psiquiátrica gallega. A base de repetirse devino con los años en un atractor semántico. Hoy ya diría que es un atractor emocional.

En la mañana de un día laborable (en "horarios de oficina") un/a paciente comenzaba su ritual de consultante primerizo/a diciéndonos: "míreme bien", "bájese bien". A las primeras consultas se le dedica más tiempo lo cual impide a veces percibir hitos patobiográficos importantes aportados en las "sucesivas". Por aquel entonces aún no había yo aprendido de los antropólogos a tomar "notas de campo". Antropología me evocaba museo, arqueología. Como mucho, médico humanista... Es decir, no había adquirido el hábito de escribir en nuestras historias clínicas (no de los pacientes) estos importantísimos preludios de los encuentros o desencuentros.

Reflexiono después de cuarenta años con el asunto de "la mirada". En los dos últimos años de mi ejercicio como psiquiatra de la medicina pública la mirada directa y abierta a los ojos del usuario se había hecho más difícil. La pantalla del ordenador donde escribía me 
requería más tiempo del imprescindible para hacer un buen contacto. No se atrevían los usuarios a decirme "míreme a la cara”... El poder de las nuevas tecnologías distorsiona la relación médico-paciente.

El formato oficial de Historia Clínica no suele tener un espacio o epígrafe que facilite ubicar estas partes. Estamos acostumbrados a cuestionar la traducibilidad cultural de escalas, cuestionarios, test, etc., pero nadie comenta que el modelo, el diseño de las historias clínicas, ya condiciona buena parte del diagnóstico. Cuando, en los últimos años de mi ejercicio profesional en el SERGAS (Servicio Galego da Saúde) hemos tenido que pasar a la historia electrónica, ésta se ha convertido en más “aséptica”. Determinadas expresiones sumamente gráficas ya no se pueden escribir.

Esas breves y concisas frases fueron pronunciadas en gallego y aquí las traduzco literalmente (conviene no olvidar aquello de traduttore, traditore) con lo cual ya las descontextualizo, las limpio de impurezas/purezas, las mutilo, las ateorizo y colonizo. Para mí, significaron algo así como un inmenso relámpago que anuncia un estrepitoso trueno. Solamente que entre el aviso (señal) y el ruido trascurrió mucho tiempo. Años de aparente silencio.

Posteriormente he necesitado otros años de silencio y desencanto, respecto al catecismo de la psiquiatría comunitaria, para que ese gran trueno generase leves reacciones (aplicabilidad) en mi praxis exploratoria, diagnóstica y terapéutica. De la aplicabilidad preventiva estamos todavía a años luz.

Ambas frases unidas pueden ser escuchadas, interpretadas, recodificadas de muy diversas maneras. No puedo yo eludir la trascendencia de la mirada vecinal-comunitaria, asociada a la envidia, como reguladora de las tensiones-uniones vecinales. Toman como referente la mirada vecinal sobre la tierra y la llevan a esa mirada acotadora del territorio, aunque en el siglo XXI ya no se trata de un espacio-territorio geográfico parcialmente reproducible en un mapa. Ahora son espacios virtuales de poder. Tal vez por ello van juntas, son inseparables. También por ello hablo de mirada descendente; de clase, de grupo, de rol, etc.

\section{LOS USUARIOS-ALDEANOS GALLEGOS (LOS OTROS)}

Los usuarios gallegos que siguen utilizando éstas y otras estrategias en las consultas (entrevistas) cuestionan todo tipo de tópicos respecto a las ambigüedades y borrosidades gallegas. Expresan directa y claramente lo que desean de una relación desigual. Explicitan su posición social, su rol y, sobre todo, creo que nos reclaman suave y mansamente que no olvidemos pobreza, desigualdad, injusticias, envidias, exclusiones, etc. Saben muy bien que buena parte de las miradas médicas y psicológicas son concienzudamente dirigidas, enfocadas exclusivamente a un punto concreto, excluidoras de lo subjetivo, de lo emocional y de lo socio-cultural para de esta manera poder dividir, etiquetar y clasificar lo que ven. 
En el dispositivo de salud mental en el que trabajaba ya habíamos aprendido a identificar esta forma de presentación-demanda cuando es dicha con estas frases. Suelen ser personas mayores de 60 años, con escasos estudios oficiales, buena parte de ellos ex-emigrantes y residentes en núcleos muy ruralizados. Lo que no hemos todavía aprendido a percibir es el mismo mensaje en personas más jóvenes, más estudiadas, más "modernas". Estamos convencidos de que también lo utilizan, pero de otra manera.

En lo que podríamos llamar mi trabajo de campo, mi observación participante, mi investigación-acción (inseparables clínica e investigación), después de casi veinte años asistimos impotentes al ocaso de las asociaciones vecinales parroquiales (territorio geográfico-comunitario) y a su parcial sustitución por emergentes asociaciones de pacientes o de familiares, siguiendo diagnósticos de manuales globalizadores (fibromialgias, bipolares, esquizofrénicos, alcohólicos, ludópatas...). Se cumple aquello de Zola (1981) respecto a la sustitución de religión por medicina como referente identitario.

Necesito insistir en que buena parte de mis reflexiones están co-construidas desde la ruralidad. Se sigue insistiendo demasiado en la patogénesis urbana (megapolis, pathopolis), tal como vemos por ejemplo en Van Os et al. (2003).

\section{ASCENDER MIRÁNDOSE (NOSOTROS)}

Para influir intencionadamente en los lectores se hace imprescindible señalar algunos apuntes acerca de la autobiografía del autor.

Socializado parcialmente (hijo de médico y de maestra rural) durante la infancia en una aldea de la Galicia interior (provincia de Lugo), al iniciar los estudios del antiguo bachillerato (a los 10 años) comencé a tomar distancia con los otros (vecinos, amigos de juegos). Distancia que se acrecienta con el acceso a la Universidad. La barrera económica era casi una muralla. De casi 5.000 habitantes del municipio, en mi generación solamente pudimos acceder a los "estudios superiores" 9 privilegiados, todos varones. Terminada la "carrera" (1966) emigro a Girona para especializarme en psiquiatría con estancias de estudios en Ginebra (Suiza). En ambos espacios me reencuentro con vecinos de infancia que han tenido que emigrar para subsistir, y en ambos el idioma y la lejanía geográfica y socio-cultural de Galicia devienen en morriña (movilizan una emoción) lo cual me aproxima a una supuesta "alma gallega, saudade" (Rosalía de Castro, García-Sabell, Ramón Piñeiro,...). El resultado inmediato es que por vez primera comienzo a leer y a escribir en la oral lengua materna.

En el año 1970 retorno a Galicia, al manicomio de Conxo. En los años siguientes el ambiente político-social y, sobre todo, la experiencia en un manicomio tradicional que inicia una reforma propiciaron una modesta politización, con militancia partidista incluida. La represión de los últimos meses o años del franquismo me destierra simbólicamente a un municipio rural e interior (Rodeiro, Pontevedra) en el cual me dejan ejercer de médico 
de cabecera durante casi dos años. Me encuentro de nuevo con esos otros aldeanos pero desde un rol de médico tradicional investido de poder local.

Colaboro activamente en lo que hemos llamado medicalización del agro. En el año 1975 se implanta en España el Régimen especial de la Seguridad Social Agraria, con significativa repercusión en Galicia. Hasta esa fecha los labradores autónomos (pequeños propietarios de la escasas tierras que trabajan, minifundismo) no podían estar afiliados al antiguo SOE (Seguro Obligatorio de Enfermedad) ${ }^{1}$, sistema mutualista de asistencia sanitaria y de pensiones de vejez e invalidez, creado por el franquismo a los pocos años de terminar la guerra civil. Diseñado inicialmente para trabajadores de la industria y para agricultores asalariados. Súbitamente los gallegos y menos las gallegas (para las mujeres la afiliación no era obligatoria hasta los 55 años) se ven obligados a pagar una contribución más (así la percibían entonces), pero que les aporta nuevas señas identitarias.

La "cartilla" (hoy ya todos le llaman tarjeta sanitaria) de la Seguridad Social les da acceso a médico, a farmacia y a hospitales no de Beneficencia; las famosas Residencias Sanitarias, eufemismo con el que el Régimen ya tecnocratizado diferencia los nuevos hospitales de los antiguos provinciales para pobres. También el derecho a una pensión (de vejez, de enfermedad, de accidente, de viudedad, de orfandad). Ya son urbanitas y españoles. Ya realizan salidas, viajes, a la ciudad por motivos médicos y para ello necesitan exhibir que tienen cartilla, que tienen los papeles en regla. En estos viajes de ida y en los retornos a la aldea siempre van acompañados, aunque luego en la consulta a menudo impongamos que el paciente pase solo... El hospital restringe y regula el acceso de las visitas; la consulta tiende a individualizar.

En este viaje sanitario reproducen los aldeanos el esquema de otros dos viajes, de otras dos salidas identitarias. Me refiero a las salidas a las romerías-santuarios (salida comunitariareligiosa) y a los balnearios (salida paisajística y autobiográfica porque al hablar con otros "agüistas" se reconstruyen). Siempre iban acompañados de familia-comunidad. Durante la ida y la vuelta se reconstruía la identidad comunitaria, anterior y superior a la individualización.

La "cartilla" (nombre que esa generación asocia inevitablemente a cartilla militar y a cartilla de racionamiento) deviene más importante que el DNI, aunque no tenga fotografía y aunque muchas de ellas en vez de la firma del titular lleven una huella digital o una trabajosa firma hecha con su mano pero guiada por la nieta o nieto que ya tiene estudios y que pronto adquiere gran protagonismo al ser "ilustrado/a" aunque no sepa arar la tierra ni atender el parto de una vaca. Es una seña identitaria importantísima. Ya

1. No se ha escrito todavía lo suficiente acerca de esta Seguridad Social, ni de los regímenes especiales: Empleadas de Hogar, Trabajadores del Mar, Agraria, Autónomos, etc.; curiosamente cuando las clases medias consiguen poder afiliarse a la misma no se diseña para ellos un régimen especial. 
tienen "papeles", si utilizamos una metáfora actualizada por la inmigración.

Pronto descubren el derecho a una paga por enfermedad, sobre todo por la columna vertebral gastada, la enfermedad profesional de los agricultores como le llamó Barthe (1990), para lo cual necesitaban tener cotizados cinco años (ahora ya son quince y cada vez serán más) y un "buen informe médico". En el momento actual asistimos a un cambio; están pasando a decir pensión en vez de paga.

Ese inmenso poder local de médico rural que firma recetas e informes (representante de la oficialidad) casi que me lleva a ser alcalde en las primeras elecciones municipales. Pero, con la disculpa de volver a la Psiquiatría, consigo reintroducirme en Santiago de Compostela. Realmente no tenía prisa este traslado profesional a la ciudad, pero hay un dato biográfico importante. Mi primera hija ya iba a cumplir los cuatro años, ya necesitaba escolarizarse y hacerlo en una aldea dicen que conlleva riesgos excluidores de cara a su futuro académico.

Unos pocos años después de retornar a la Psiquiatría y a la Ciudad, puedo elegir ser miembro de un equipo interdisciplinar de salud mental; psicólogo, psiquiatra, enfermera, trabajadora social y auxiliar administrativa. Dejo para otro espacio y lugar comentar esos mitos de trabajo en "equipo" y de la "multidisciplinariedad" que necesitarían de dos o más artículos para leerlos antropológicamente.

La USM (Unidad de Salud Mental) atendía inicialmente una población rural y dispersa a unos 30 kilómetros de Santiago de Compostela.

Era, entonces, una sociedad rural tradicional en acelerado proceso de cambio socioeconómico y cultural. La agricultura se estaba modernizando y pasaban ya algunos a ser productores de leche o de carne. Ya sufrían el tema de las cuotas lecheras impuestas por la Unión Europea. Sus hijos ya pretendían ir a la universidad, huir de la aldea. Nos encontrábamos con un alto porcentaje de analfabetismo en mujeres mayores de 60 años, con tasas altísimas de suicidio, con un aumento espectacular de consumo de alcohol en una zona en la que no puede crecer ni una sola cepa de vid, con varios emigrantes en cada familia (primero a Brasil y después a Suiza). Sin atisbos de industria y con un sector servicios (bares, casas de comidas, tiendas, servicios municipales) en constante incremento.

Gozábamos entonces de un cierto ascendiente sobre las incipientes Gerencias de Primaria y de Hospital; la racionalidad económico-administrativa todavía no se notaba gran cosa. En esa comunidad (la primera pequeña capital municipal gallega que dispuso de una USM), porque así lo decretamos y porque así nos interesaba al equipo, implementamos una modesta USM rural. Nos desplazábamos desde la ciudad un día a la semana a consultar en el edificio del Centro de Salud; ellos, los usuarios, le siguieron llamando Centro Médico durante muchos años. Al final va calando el término Centro de Salud.

Nos quedábamos a comer en la capital municipal precisamente en el momento en que prácticamente la mayoría de los médicos, de los farmacéuticos, de los profesores de 
primaria y secundaria ya se iban a comer y a dormir a las ciudades. Los curas empezaban a escasear y a ser cada vez más viejos, cada uno tenía que atender varias parroquias. Por las tardes realizábamos consultas domiciliarias (visitábamos las casas, las olíamos, etc.), teníamos reuniones con servicios sociales y, sobre todo, comenzábamos a interaccionar con una única parroquia a partir de la llamada de la Asociación de Vecinos que se encontraban preocupados por la tasa de suicidios consumados.

En los últimos años ya no podía desplazarme ni cada dos semanas a las aldeas. La presión asistencial de otros municipios más próximos a Santiago que se urbanizan aceleradamente, las pegas burocráticas (al pasar a depender jerárquicamente de un Hospital no entienden nada de esos viajes) y el gran poder que han ido adquiriendo las Gerencias hospitalarias me condicionan cada vez más a un trabajo de despacho, a una psiquiatrización biologicista de mi praxis asistencial, a un recetador de fármacos. La industria aún no ha diseñado una pastilla para la comunidad.

Los usuarios rurales han de desplazarse al Ambulatorio Concepción Arenal en Santiago de Compostela con lo cual se va a producir una exclusión, una dificultad en la accesibilidad, en función de la edad, medios de transporte, medios económicos, estado físico, etc. Les sigo "recibiendo" en mi "despacho". Ya no entro en sus casas, ya no acudo a reuniones vecinales en los anocheceres (cuando están todos en las casas), ya les es muy dificultoso venir toda la familia. También constatamos cómo cada vez hacen más uso de ese nuevo espacio y nueva cultura de las Urgencias hospitalarias que, lógicamente, aumentan al anochecer. Allí, por supuesto, no pueden atenderles como intervención en crisis. La escucha es tecnológica, de aparatos-instrumentos. Nadie sale de ese espacio sin un análisis y sin un electrocardiograma aunque se los haya hecho dos días antes en su Centro de Salud.

\section{PSIQUIATRIZACIÓN Y EDUCACIÓN FAMILIAR DEL AGRO (NOSOTROS Y ELLOS)}

Volviendo a metáforas, nosotros (el equipo de la USM) hemos realizado una cruenta intervención cultural. Colaboramos activamente en la psiquiatrización del agro. Tal vez no hemos sido más que meros instrumentos, meras agencias, de otros visibles o invisibles poderes muchísimo más fuertes que tienen capacidad, intencionalidad y medios para diseñar y propiciar bruscos cambios culturales en aras de la modernización-globalización. Con la distancia de los años, la reflexión nos lleva a pensar que no hemos hecho más que lo que los medios de comunicación y otros poderes estaban introduciendo sutilmente. Las primeras USM gallegas fueron totalmente diseñadas desde Madrid, desde una gran urbe. Eran del INSALUD (Instituto Nacional de la Salud) que tardó años en ser transferido al SERGAS.

Basta señalar que desde Madrid, desde la capital del estado, psiquiatras tecnócratas al servicio de lo que entonces pensábamos era un gobierno de izquierdas, nos impusieron 
entre otras cosas el modelo de Historia Clínica. Es decir, el instrumento y el formato en el que debíamos recoger la información que nosotros queremos, no la que quieren dar los usuarios. También obligaron a las gerencias de atención primaria a que nos dotasen a todas las USM de un "manual", de un catecismo adoctrinador, que resultó ser la DSM (Diagnostic and Statistical Manual of Mental Disorders, de la Asociación Americana de Psiquiatría). Colaboramos pues en diseñar una USM española, urbanita, de los profesionales no de los usuarios, de enfermedades no de salud.

Con estas armas y con el rol de "especialistas" que se desplazan a la aldea, generamos o recogimos una inmensa demanda a la que debíamos poner etiquetas DSM. Para ellos "especialista", por aquel entonces, hacía referencia a alguien que sabe más de todo, incluidas leyes, partijas, concentración parcelaria, normas de conducta de los jóvenes, argucias, etc. Es decir, alguien revestido de "poderes" en el sentido mágico-supersticioso según el discurso de la biomedicina. Psiquiatrizamos el agro.

Ayudamos a reconstruir problemas políticos, sociales, comunitarios y familiares pasándolos a diagnósticos "psi" que siempre han sido individualizadores por mucho que se añada lo de "social".

A aquellos usuarios inmensamente "cultos" en una cultura monista les impusimos el dualismo. A quienes sabían expresar, con infinidad y riqueza de matices, su malestar en un lenguaje oral-corporal, les llamamos somatizadores, término que ni el mismo Kirmayer (2001) a pesar de sus brillantes análisis estadísticos acaba de entender. A quienes "bebían" alcohol como hacemos nosotros, les respondíamos diciendo que "ingerían" equis gramos de etanol por día. Tasamos esa ingesta al margen del contexto y del modo en que se bebiese. A los numerosos usuarios que nos venían diciendo que tenían nervios (constructo producido por los médicos en otras épocas) nunca hemos puesto ese diagnóstico en las historias clínicas y lo transformábamos en Ansiedad, Depresión, Somatización. Como mucho, Neurosis.

Cuando ellos hablaban de locura, igual que lo hacemos nosotros a nivel coloquial y literario, y de los diferentes grados y tipos de la misma, nosotros respondíamos diciendo que ahora se dice Psicosis o Esquizofrenia. Cuando nos hablaban de antiguos y gráficos términos como males de la cabeza les obligábamos a escoger entre Neurología y Psiquiatría. En el territorio persiste una Romería-Santuario especializada en males de la cabeza. Cuando su médico de cabecera u otro especialista, en los desencuentros y disonancias, les había dicho "usted no tiene nada" nosotros lo nominábamos con algunas de las etiquetas de la DSM, incluida conversión, trastorno facticio, trastorno de la persona(lidad), etc. Aceleramos la individualización, el anonimato de lo social. Los saberes más locales o populares que se generaron en la historia de una persona fueron marginados.

Nunca hemos sabido escuchar su rico y variopinto lenguaje emocional. Como mucho, a la "pena" le llamamos tristeza y lo metíamos en Depresión, y a la "ansia" (concepto 
positivo y no perturbador en su cultura) en más de una ocasión la confundimos con Ansiedad. Otras emociones, como la ira, la rabia, la cólera, al no estar aún medicalizadas no las considerábamos "motivo de consulta". El solapamiento y la borrosidad es norma en el vocabulario emocional.

Tampoco sabíamos descodificar eso de "no duermo bien" o "no descanso bien" y siempre lo convertíamos en psicopatología, en insomnio. Ya no digamos nada de las relaciones del sujeto con la comida. Todos estos y otros muchos constructos culturales de nuestra medicina venían reforzados por nuestro poder para dar una baja laboral pagada (subvencionada) o una pensión de invalidez. Cual tontos o inocentes investigadores nos sorprendíamos después de que el vecino se quejase (envidiosamente) de que a él no le dábamos esa prebenda. Atribuimos estas envidias a persistencias, a rémoras de su "atrasada" cultura.

En ese míreme bien que comentábamos al principio también hay un matiz, un componente, del "buen ojo" frente al "mal ojo", estrechamente relacionado con la envidia. Igual ocurre con los "aires"; es decir, que un paciente pueda "coger" un "aire" siempre lo interpretamos como negativo, obviando que cualquier ser vivo o recientemente muerto emite siempre aires que la mayoría de las veces son "buenos", beneficiosos. Si estamos en un cambio de Religión a Medicina los médicos también tienen "poderes” especiales. Cuando los jóvenes de ahora hablan de "química", o los ya maduros de "empatía", ¿tal vez se están refiriendo a los antiguos "aires"?

Cuando llegamos al territorio rural solamente había una Trabajadora Social municipal tres días a la semana. Compartía su labor con otro municipio colindante, que no pertenecía a nuestra área asistencial. Mapa Sanitario, Mapa Escolar y Mapa de Servicios Sociales no coincidían, a pesar de que en varios gobiernos del ente autonómico (Xunta de Galicia) era el mismo consejero y Consejería para Sanidad y para Servicios Sociales. Cuando dejé de desplazarme al territorio ya eran varias las Trabajadoras Sociales y, para complicar más el clientelismo interinstitucional, acababan de nominar a una Educadora de Familia. Inicialmente este puesto lo ocupó durante años una recién licenciada en Filosofía. El diseño también vino impuesto por reparto de poder entre "barones" del partido que gobernaba y gobierna aún hoy Galicia. Para mantener el equilibrio tuvieron que crear una Consejería de Familia y su titular necesitaba reproducir en todas las provincias una red clientelar con la que sostener a su “patrón” en Lugo.

Recuerdo a una usuaria de la USM a la que por presión de los Servicios Sociales hicimos un diagnóstico de alcohólica en rehabilitación. De esta forma podía acceder a una pequeña paga mientras se curaba... Un día llegó a la consulta toda enfadada, "por favor se lo pido, por el alma de sus difuntiños no me mande más a casa a la Asistenta que solamente le falta mirar si llevo las bragas limpias...". Se refería de esta forma a la "educadora de familia", a la cual por supuesto nosotros no habíamos enviado a esa ni a ninguna otra casa. Pero la moza necesitaba acreditar un número determinado de intervenciones domiciliarias para 
que la Xunta siguiese financiando el "programa” y ella continuara contratada.

Se iniciaba pues la educación familiar del agro. ¿Se suponía que previamente estaban mal educados? Sencillamente estábamos asistiendo a la emergencia del Espacio Socio Sanitario. Ya disponíamos de un lugar en el cual depositar los residuos sanitarios y sociales. No es por casualidad que por aquel entonces los medios de comunicación daban cuenta de un encarnizado debate político, no sólo entre la oposición y el gobierno gallego sino dentro del propio partido del gobierno. Se debatía el cómo y el dónde depositar y tratar los residuos, la basura. Como en este caso era muy fácil ver intereses económicos, el asunto era y sigue siendo noticiable. La gestión de los residuos sanitarios también se traduce en costes no sólo económicos; pero son menos visibles, más sutiles.

\section{LOS OTROS Y LA PSIQUIATRÍA COMUNITARIA}

Teóricamente ya no existían trabas para hacer Salud Mental y/o Psiquiatría Comunitarias. Seguíamos culpando a la administración de nuestras propias contradicciones. No culparla sistemáticamente conllevaría preguntarnos por nuestras propias creencias, por nuestra propia cultura. Repetíamos tópicos de otros catecismos, pensando que con enunciarlos ya era suficiente. Trabajo en equipo, interdisciplinariedad, participación comunitaria, psiquiatría popular, etc., hemos ido viendo cómo en las praxis cotidianas se obvian apoyándose en todo tipo de discursos.

Pensábamos que con decretar el cierre de los manicomios ya estaba todo resuelto. En los últimos años de la abortada reforma de Conxo (1972-1975) habíamos colgado la blanca bata, símbolo de la asepsia e instrumento de diferenciación, y comenzamos una tímida descentralización de la institución abriendo "dispensarios" en las ciudades y en algunas villas importantes. Era una modesta sectorización, preludio de una posterior psiquiatría comunitaria que aún está por llegar.

La industria farmacéutica ya estaba mirando con muy "buenos ojos" a los gestores de esos pacientes externalizados y a las nuevas demandas de los que nunca habían consultado ni nunca iban a ser ingresados. Los percibía como un inmenso potencial de consumo. Les venía de perlas esa pseudoliberación (¿liberalización?) de la locura. Sabían que fuera de los muros de la institución tradicional necesitaban solamente crear necesidades a través del marketing y de la publicidad y disponer de intermediarios, de recetadores que incluso ya no tenían que ser solamente los psiquiatras. Otra pseudorreforma, la de Atención Primaria, propiciaba también sus intereses.

Lo importante ahora era que al salir del manicomio nos volvíamos a encontrar cara a cara con supersticiones, con creencias de los usuarios, con valores, para los cuales ya no teníamos la defensa virtual o real del muro. Nos reencontrábamos con la diferencia y el estar más cercanos geográfica y espacialmente condicionaba volver a ponerse la blanca bata.

Esos otros seguían siendo para nosotros (médicos oficiales urbanitas) una estructura en 
vez de un proceso. La falta de formación filosófico-social continuaba representando una pesada piedra, un poderoso lastre, que nos llevaba río abajo hacia el folclorismo, hacia los exóticos CBS (Charles Bonnes Syndrome) -apoyados por las tonterías que dicen la CIE (Clasificación Internacional de Enfermedades de la Organización Mundial de la Salud) y la DSM- , hacia la etnopsiquiatría. Cierto es que los antropólogos y sociólogos ya hablaban de potsmodernismo, de aldea global y de autor. Pero, para los psiquiatras que aún siguen anotando en las historias "nivel cultural bajo" para referirse al nivel de estudios o de "sus labores" para referirse al rol/profesión de ama de casa de muchas mujeres, ese discurso socio-cultural quedaba muy lejos, entre otros factores porque los miembros de la generación de la Reforma Psiquiátrica española no hemos sido capaces de co-construir, con los usuarios y con la comunidad, una cultura y unos contenidos de auténtica Psiquiatría Comunitaria.

En este contexto no es de extrañar que ante otros y ahora el conspicuo Tizón (2013) propugnase la necesidad de volver a meternos claramente en política. El discurso sobre la distancia aparece como un intento de mantener la neutralidad y la asepsia políticas. Investigando y teorizando sobre unos "otros" lejanos geográfica, social o culturalmente tanto el antropólogo como el psiquiatra trans-cultural no necesitan enfrentarse a situaciones sociales subalternas que están aquí. Esos otros pueden ahora ser los inmigrantes. Es más atractivo escandalizarnos y prohibir por decreto sus velos (los reales, porque a los virtuales no tenemos acceso) o las macroagresiones como las de Irak que investigar sobre las microagresiones culturales (Pierce, 1986) que día a día estamos realizando activa o pasivamente en nuestras cruentas entrevistas-intervenciones culturales.

Difícil diálogo interdisciplinar entre psiquiatras y antropólogos. Visto desde abajo, desde alguien que mientras actuaba de psiquiatra en el rural gallego, era un añoso alumno de tercer ciclo, los profesores de Antropología y de Sociología conservan un cierto poder feudal-medieval expresado en el concepto "libertad de cátedra" o en el de "autonomía universitaria”. Las/los trabajadores sociales, las/los enfermeras/os, y algo menos las/os psicólogas/os y psiquiatras estamos sometidos a un rígido corsé de normas, de relaciones laborales con el empleador-pagador, de colegios profesionales, de leyes que producen los poderes públicos, etc., que nos ubican frente a los investigadores y docentes como peones de albañil frente a los arquitectos.

\section{ACCIÓN - INVESTIGACIÓN}

Como psiquiatra "clínico" (el lector puede leer "cínico") invierto el orden en el cual suelen poner los "teóricos" (los que son sólo científicos docentes) estas dos palabras. Estoy plenamente convencido de que para avanzar la secuencia debe de ser como yo la escribo.

Cuando ya llevábamos algún tiempo actuando en dicha USM rural, se hizo más estrecha 
mi relación con un antropólogo gallego, con Marcial Gondar. Sin darnos cuenta, sin haber diseñado un "programa con objetivos", día a día ambos fuimos convirtiendo el espacio de una cafetería compostelana en un auténtico "laboratorio". Varios días de cada semana necesitábamos “tomar un café”, hacer un alto en nuestras respectivas ocupaciones vespertinas. Escuchando o hablando, teníamos una inmensa ansia de desconectar con las horas pasadas y con las venideras. Transcurrido un breve preludio de cotilleo, alguno introducía: "estoy leyendo..., "acabo de escribir..., "acabo de ver a un paciente que me ha dicho..." Luego de diálogos o de monólogos, volvíamos (pero ya algo cambiados) a nuestros diferentes quehaceres.

Sabíamos previamente que lo más jugoso y formativo de los congresos, seminarios, clases, etc. son siempre los "cafés", los comentarios de pasillo, las cenas y las borracheras conjuntas. Es decir, lo bueno, lo útil, lo aplicable, lo que transciende, surge casi siempre en espacios en los cuales está permitido emocionarse, drogarse, interactuar sin excesivos corsés.

Aunque se hubiese conseguido la utopía de que la Administración Sanitaria nombrase a Marcial como asesor antropológico de la USM o aunque se hubiese producido la posibilidad real de que Emilio formase parte de un Proyecto de Investigación de la Universidad dirigido por Marcial, los resultados nunca iban a ser los mismos y, sobre todo, no se podrían aplicar... A través de esos cafés pronto Marcial se convirtió en un miembro virtual del equipo de la USM que en ese momento sí que fue interdisciplinar. Juntos visitamos varias veces (siempre aprendiendo algo nuevo) a Freire, un sanadorvidente. Un "sabio" con "poderes", en el decir de nuestros usuarios, que nos derivaba pacientes a la USM y a quien yo le sigo pidiendo (por supuesto sin volante, sin papeles) interconsulta de algunos casos. El problema es que ni puedo anotar estas derivaciones en las historias clínicas ni puedo contabilizar ese tiempo como actividad asistencial. Por un casual, Freire antes de dedicarse a "enfermedades no de médicos" (término tomado de Platón a quien creo que él no ha leído y yo muy poco) había sido paciente mío en otro dispositivo psiquiátrico público.

Ya antes de que Marcial se "incorporase” a la USM había visto necesario ir a su reencuentro después de muchos años de distancia, al comprobar que era el "curador no oficial" con el que compartía usuarios aunque ejercía en otro municipio. No podemos olvidar que es rarísimo que uno de estos sanadores atienda a sus propios vecinos. Algo de distancia se necesita. De ahí, que cuando intentamos disminuir la brecha cultural entre médicopaciente nunca propugnemos eliminarla totalmente.

Con Marcial y con otros miembros del equipo real, "viajamos" no pocas noches a reuniones-coloquios con la directiva de la Asociación de Vecinos de Bazar, pequeña aldea del municipio de Santa Comba, muy cerca de Santiago de Compostela, y a algunas con toda la comunidad parroquial. No es por casualidad que en dos o tres ocasiones 
nos extraviásemos en las pequeñas carreteras sin señalizar, sin rotular; a ellos no les hacen falta letras/letreros indicativos... También en estos encuentros tomábamos "cafés" y dulces monjiles ${ }^{2}$. Al percibir-interpretar conjuntamente que la identidad parroquial estaba perdiendo contenido y utilidad, y que ellos lo notaban más en los jóvenes (?), se decidió impulsar un periódico mensual confeccionado por esos adolescentes (todavía sin anorexias, bulimias, ni adicciones al móvil) con variopintos contenidos, letras muy grandes y distribuido por todas las casas-familias, para luego poder ser contestado o matizado oralmente. Su tradicional cultura era casi totalmente oral u opacada a través de la expresión corporal. Todos los mayores eran muy habilidosos en crear poesía.

Hasta hacía pocos años la comarca disponía de la Regueifa, un sofisticado ritual de desafíos verbales en el que se puede y se debe ofender ritualizadamente al oponente siempre que sea en pareados versos. Ahora forma parte del patrimonio museístico. Antes amortiguaba conflictos comunitarios. A veces, experimental y tímidamente, hemos utilizado parte de esta técnica en las consultas psiquiátricas. Aunque haya desaparecido el ritual les encanta debatir con el médico y ganarle si es posible a través de ironías, bromas, refranes, etc. De aquí también apuntamos aquello de soluciones locales coherentes con la pluralidad europea que consideramos aplicable a la gestión clínica de malestares en general.

Claro está que al final los médicos "escribimos", recetamos, informamos. Tenemos el poder de la pluma de los antiguos escribanos. ¿Por qué será que la industria farmacéutica siempre nos regala diseñadísimos bolígrafos, lapiceros, rotuladores, etc.? La relación médico-enfermo es una regueifa con perdedor ya señalado antes de empezar. En los viejos rituales el desafío lo perdía aquel a quien ya se le terminasen las palabras, aquel que fuese incapaz de crear una nueva y rimada poesía que comenzase justamente con la última palabra salida de la boca de su oponente. Esa palabra bien-dicha (bendita como la del ritual religioso), una vez pronunciada adquiría autonomía y poderes propios.

En uno de esos coloquios vecinales, debatiendo únicamente un caso clínico, el de Manolo (diagnosticado oficialmente de esquizofrenia residual) sacamos una interesante conclusión acerca de la gestión de los psicóticos rurales. Como alternativa al mitificado case management acuñamos aquello de psicóticos vistos como vecinos. En cuanto conocimos los pareceres de sus vecinos y lo integrados que estos pacientes estaban, en las consultas-revisiones del caso concreto apenas nos deteníamos en las alteraciones psicopatológicas. Al ubicarlos como a otro cualquiera de los miembros de la comunidad la entrevista cambiaba radicalmente. Manolo también "sabía".

Todos los pacientes saben, si les dejamos hablar, si introducimos en la entrevistas atractores semántico-emocionales en vez de bloqueadores narrativos (preguntas de

2. Parte de nuestro trabajo se ha apoyado en la previa labor de muchos años de una pequeña comunidad de monjas que había conseguido permiso para dejar el convento-colegio y trabajar con y para la comunidad. 
manual, de escala, de tratado de psiquiatría). Respecto a la respuesta popular a la locura, al trastorno mental severo, en la comarca, igual que en otras zonas de Galicia, se venía produciendo desde hace muchos años el encierro, la reclusión en una celda doméstica (González, 1988) modelo que coexistió con el encierro manicomial.

Conjuntamente con Marcial sostuvimos varias entrevistas informales con el alcalde, con la directora del colegio público y con el jefe de estudios. Aceptamos su demanda de expertos en folclore (no solo etnográfico sino también psiquiátrico modernista) para reconvertirla en otra cosa. Es decir, escapamos de populismos. Con su ayuda y a través de los alumnos de $6^{\circ}$ y $7^{\circ}$ de EGB (Educación General Básica), se recogió una inmensa cantidad de patrimonio cultural no material y nunca escrito. Los abuelos de esos niños y los viejos en general de cada aldea se convirtieron en informantes, en piezas indispensables para que estos alumnos-nietos cumpliesen con sus deberes escolares. El resultado fue un libro Cousas de vellos na Escola de.... (Cosas de viejos en la Escuela de...), en edición no venal, escrito en letra grande para que pudiese ser leído-comentado-complementado por los viejos. El siguiente paso fue que orgullosamente algunos alumnos llevaron a sus abuelos al aula. Allí se convirtieron por unos días en profesores. De allí salió aquello de los viejos como recurso cultural, una modesta, pero nada despreciable alternativa a la problemática de exclusión que comenzaba a emerger con la mecanización de la explotación agraria. Por supuesto que seguimos los procedimientos canónicos y nos entrevistamos con todo tipo de líderes y de agencias que ejercen en esa comunidad, por ejemplo Extensión Agraria - Concentración Parcelaria. Con mi tesis doctoral ya escrita nos dimos cuenta de un importante error. Habíamos olvidado a unos importantes intermediarios culturales: los mancebos de farmacia. Ahora ya quedan pocos; la mayoría son farmacéuticos. Cuando el paciente sale del médico con las recetas, sistemáticamente tiene que ir una Farmacia. Allí es donde completa el acto médico. El mancebo refuerza o cuestiona la prescripción y casi siempre tiene que ponerle en las cajas del medicamento la hora y la cantidad que debe tomar. Los médicos del siglo XXI ya no escriben la prescripción en latín; sin embargo persiste el mito de la "letra de médico" que el boticario debe de interpretar. Cuando se habla de las rutas asistenciales suele olvidarse el camino de retorno a la casa-familia. Analizando las salidas a los santuarios-romerías nos dimos cuenta de que al salir del centro médico se prosigue esa ruta sanitaria, prosigue la inacabada construcción de los enfermares y de la salud.

También por aquellas fechas Marcial y yo viajamos a la "catedral" de la antropología médica aplicada. Nos referimos a la Rovira i Virgili de Tarragona. Íbamos como invitados a alguno de los cursos de Comelles, Martínez, Oriol, etc. pero yo siempre me sentí alumno. Allí conocimos personalmente a algunos de los “dioses". Solamente citaré al influyente Kleinman, un auténtico acróbata en lo que dice y en las sombras de su discurso..., y al sólido y coherente E. Menéndez. Ambos han influido significativamente en mi accióninvestigación. 
Lo que podemos llamar cultura médica o cultura psiquiátrica oficial, como todas las culturas y subculturas, está aún en proceso de construcción. Puede permitirse ignorar a la antropología, también a la psicología, pero necesita seguir dándose codazos con otras especialidades médicas. Se hace fácilmente visible en el conflicto con los neurólogos acerca de los diagnósticos de las demencias. Temen algunos psiquiatras que pasen enteramente a la neurología como ha ocurrido con las epilepsias.

Señalo ya desde el principio que no tenemos resuelto el problema de la aplicabilidad a la clínica de todo lo que están produciendo las diferentes orientaciones de la antropología social o cultural. Ni somos capaces de verlo en un horizonte próximo. Esta dificultad de hacer operativas en la praxis cotidiana brillantísimas aportaciones debería hacernos reflexionar... Cuando en los siglos pasados los antropólogos eran requeridos por las administraciones de determinados países para unos fines concretos, su papel estaba de antemano explicitado.

El problema es que aquí y ahora el sistema nacional de la salud, normalmente, no les llama, a lo sumo les puede requerir como folcloristas, como acompañantes secundarios, como historiadores, etc. ¿Necesitan adecuar su discurso si desean acercarse al poder médico? ¿Qué impacto han tenido en la psiquiatría americana y española las excelentes aportaciones de nuestros admirados B. Good y A. Kleinman? ¿No estaremos eludiendo alegremente la heteroglosia existente en el concepto Antropología de la Salud?

Los emigrantes que no emigran ha sido otra parte no siempre bien desarrollada. Asistimos al retorno de muchos vecinos que pasaron quince o veinte años en ciudades de Suiza, Holanda, Alemania, Francia, pero que no quisieron (?) integrarse en esos países. Donde hay poder siempre hay resistencia, decía Foucault (1997:16). Por carta y luego por teléfono, continuaron siendo miembros activos de su comunidad parroquial. $\mathrm{Al}$ enfermar, al envejecer o al tener ya años suficientes para "disfrutar" de una pensión, vuelven a su comunidad de la que nunca se han ido... Creo que la gestión de las locuras y de otras dolencias de los inmigrantes que acuden masivamente a España va a ser gestionada en sus países de origen. En cuanto dejen de ser productivos, ¿los vamos a expulsar favoreciéndoles el retorno?

\section{DISONANCIAS (SIN COMENTARIOS PARA QUE EL LECTOR LAS RELLENE CON SU AUTORÍA)}

Caso Casimiro. A poco tiempo de abrir la USM rural todos los "aldeanos" quisieron "darse" una consulta con el "especialista de los nervios". Casimiro vivía solo. De talla baja y recia complexión, cubría la cabeza con una boina que se saca nada más entrar por la puerta. De pocas hablas. Decían que era muy suyo, pero buen vecino. Durante muchos años había trabajado duramente en las minas de wolframio. A pesar de sus setenta años aún caminaba con pasos de oso grande.

Entró en el despacho con la cartilla sanitaria en la mano. Era su manera de señalarme sus 
derechos. No quiso sentarse:

-¿No tendrá por ahí unas GOTAS para dormir?

Ni se me pasó por la cabeza contestar que se preguntara a sí mismo que era lo que le quitaba el sueño. Apenas quedaban ya medicamentos en gotas. Todo en cápsulas o pastillas. Le receté un antiguo pero potente producto e indiqué que lo tomase por las noches después de la cena ${ }^{3}$. Se marchó dando las gracias.

Dos semanas después se presentó sin cita:

-Las gotas eran muy fuertes. Me bajan la tensión y no pude tomarlas.

-¿Y luego quién le ha mirado la tensión?

Sabía que era analfabeto, iletrado, y aún no había llegado la moda de tener en casa aparatos para medirla. Podía ocurrir que viviese cerca de una enfermera o de un practicante.

-Se las he dado a los gatos y se atontaron. Uno de ellos llegó lleno de barro, debió caerse por un barranco. Otro que es muy bravo y no deja tocarle se volvió manso de todo.

Mucho me hizo cavilar. Él no podía leer los prospectos ni quería que los vecinos conociesen su insomnio. Había recurrido a estrategias, a habilidades propias de su subcultura. Tenía cerdos, gallinas, perros y algunas ovejas. Para "probar" los efectos del fármaco utiliza un animal poco valorado que no significa gran pérdida si fallece. Solicita gotas por ser más fáciles de mezclar con la leche o el caldo que las pastillas.

Casimiro no sabía que etimológicamente fármaco es el mismo vocablo que veneno. Pero había aprendido a defenderse. Era iletrado pero portador de una rica cultura que aconsejaba desconfiar de los saberes oficiales, de la administración, de los intermediarios (en este caso los médicos). También aprendiera que cualquier producto puede ser beneficioso a unas dosis y venenoso a otras.

Al mirar el presente veo a Galicia como la más drogodependiente de toda su historia. Aceptamos como normal medicalizar el más pequeño malestar. Un ligero temblor de manos, una mínima irritabilidad, unas horas de insomnio, un pequeño bajón en el estado de ánimo, ya es suficiente para que el entorno familiar, social y profesional nos fuerce a tomar antidepresivos o ansiolíticos. La tristeza se convierte en depresión y la timidez en fobia social. Por lo tanto hay que tratarlas como enfermedades. Me pregunto qué va a ocurrir en los nuevos pobres del 2013 con los NES (Síndrome de Comedores Nocturnos).

El mito del Centro de Salud. Poco antes de conocer a Casimiro, en la capital municipal se había construido un Centro de Salud. Al comenzar a ocuparlo llovía dentro y fue necesario cambiar ventanas, etc. Ya señalamos antes cómo durante mucho tiempo los usuarios le seguían llamando Centro Médico. Tenían razón. Era un centro de poder y

3. La forma, el color, la textura del fármaco era entonces un elemento clave en su cosmovisión. Si no le indicamos antes o después de las comidas nos lo van a preguntar. Al decirle "después" de los alimentos le estoy trasmitiendo que es un remedio potente, que no debe tomarse con el "estómago vacío". 
colonización. Era un centro de poder y colonización interna. La Ley General de Sanidad del año 1986 define, entre otras funciones, a los Centros de Salud como "lugar de reunión entre la Comunidad y los Profesionales Sanitarios" (art.74, c). Esta función nunca se llevó a cabo...

Frente a la idea de que el valor más apreciado de Occidente se alcanza cuando se pasa del Mito al Logos, seguimos defendiendo la convivencia entre ambos. Incluso la utilización de gramáticas míticas como herramientas terapéuticas en la relación médico-paciente. Razón frente a seducción.

Buena parte de las estrategias y habilidades del pasado han sido barridas o subalternizadas por el actual modelo médico hegemónico. Sin embargo, tenían una capacidad terapéutica y de compensación social a años luz de las alternativas pretendidamente de progreso. Lejos de canonizar el pasado, partimos del supuesto de que todos los momentos históricos son polivalentes y que en habilidades como las de Casimiro había positivos elementos compensatorios.

Frente a la imagen de fragmentación (cadáver troceado) sobre la que está construida toda la medicina hegemónica occidental, la cosmovisión gallega tradicional tenía una visión holística de la persona enferma que no la limita a su dimensión bioquímica. Ofrece este aspecto ricas posibilidades terapéuticas.

Necesitamos hablar de saberes subalternos, profanos, para recuperar saberes culturales, silenciados, opacados, despreciados por los "saberes expertos". La creciente medicalización (drogas para mejorar la autoestima, drogas para olvidar...) acaba destruyendo saberes acumulados históricamente. Los saberes locales y los personales (de experiencia vital) son negados por la violenta epistemología que jerarquiza el saber.

El caso Gloria es el de una paciente de 57 años, casada, con estudios primarios incompletos y que vive en una aldea de un municipio colindante con Santiago. Era agricultora y ahora ya es pensionista por enfermedad. Convive con su marido de 57 años que sigue empleado en una fábrica, con su soltera madre de 74 años y con una tía materna, de 75 , también soltera. Ha tenido un único hijo ya casado que vive no muy lejos. Acude por vez primera a la USM el día 27 de noviembre de 2003 derivada por el servicio de Reumatología del Hospital con un volante de interconsulta en el cual la reumatóloga ha escrito (el subrayado es nuestro):

"Tendinitis de los Rotatorio crónica + patología vertebro lumbar crónica. Sentimiento de infelicidad, ganas de llorar frecuentes, apatía, abulia. Su patología reumatológica no justificaría la severidad de sus sentimientos. Ruego consulta y/o tratamiento. Saludos". Nos muestra Gloria un informe de Neurología que dice:

“... 1) Claudicación intermitente neurógena por estenosis raquídea. 2) Polimialgia reumática. 3) Hipertensión arterial.- Se ha indicado cirugía que ha sido desestimada por Neurocirugía.- Se puede ensayar calcitonina y calcio que ocasionalmente demostraron 
mejoría de la claudicación en pacientes no operados".

$\mathrm{Al}$ preguntarle ¿qué le pasa?, al facilitar que se descosifique y se reconstruya, responde (en un gallego que traducimos como podemos):

"Yo trabajando era la mujer más feliz del mundo... Lo pasaba mejor que en cualquier romería... y ahora no puedo trabajar y lloro siempre por no poder trabajar", "Mi vida la llevo en lágrimas", "Ya me sentiría algo feliz si por lo menos pudiese limpiar mi CASA...", "Para mí el dormir era sagrado; ahora no duermo y me acuerdo de cosas de hace 50 años", "Sí, tengo ANSIA de todo, pero no puedo hacer nada. Salgo a pasear con mi marido por las tardes cuando regresa del trabajo.", "Tengo inquietud que no me deja estar quieta, pero a veces me caigo", "Tengo continuamente PENA por no poder hacer....", "Tengo un buen marido, un buen hijo, una buena nuera...", "Solamente me hace reír algo la nietecita de un año que tengo, pero hasta no me atrevo a cogerla por si se me cae de los brazos...", "No doy comprendido lo que han hecho conmigo. Yo estaba pagado el Seguro Alto 4 para tener derecho a las Bajas, y a poco de coger la Baja ya me llamaron de Tribunales ${ }^{5}$ y me dieron la INVALIDEZ sin pedirla".

En el momento actual la Cultura influye de manera destacada en la Medicina, no por status cultural de los pacientes y sus familias sino por el bagaje cultural de médicas, enfermeras y otros profesionales de la Salud. Ya estamos acostumbrados a escuchar términos relativamente modernos tales como "accesibilidad cultural" al sistema sanitario y "competencia cultural de los hospitales". Pero siempre refiriéndose al status cultural de los pacientes o usuarios. Los valores que impregnan la educación para la salud y la práctica clínica quedan oscurecidos, sin explorar ni investigar.

Los sanitarios llevan a las consultas, a los hospitales, a los órganos de gestión, etc. abundantes valores que ayudan eficazmente a la homogenización cultural y a la globalización. Teniendo en cuenta que la Cultura invade el espacio mente-cuerpo y modela la salud y la enfermedad, se hace imperioso aproximarse a "partes negadas de la Cultura".

Pilar se está acercando a los 50 años. Trabaja duramente en una industria conservera. Le gusta leer libros de autoayuda y divulgación psicológica. Ha llevado a un hijo adolescente al psicólogo y más de una vez nos ha traído a Gervasio, su marido, a la consulta; a él le gusta ir unas horas a la taberna al salir del trabajo. Ella pretende que se venga para casa

4. En el Régimen Especial de la Seguridad Social Agraria los afiliados llaman "seguro alto" a pagar una sobretasa para tener derecho a disfrutar de bajas laborales temporales.

5. Siguen llamando "Tribunal" a la Comisión de Evaluación de incapacidades o invalideces. Cuando les citan se sorprenden de que en vez de un Tribunal solamente se encuentren con un inspector médico. 
y salgan a pasear o se pongan a comunicarse. Siente Gervasio vergüenza de salir casi siempre con su esposa mientras que los otros hombres están en el bar.

"Estuve leyendo Amor Inteligente y me ayudó mucho. Le dije a Gervasio que teníamos que hacer un cursillo de besos... No funcionó. Él no ponía pasión.- Hoy hemos venido todo el viaje sin hablarnos. Está enfadado porque el sábado le he dicho que tenía reservada plaza en el Autobús de Mujeres que va casi todos los fines de semana a Vigo a la Discoteca de Mujeres Separadas...Al final no ocupé mi plaza...”

Silvia es una argentina de 35 años (hija de padre gallego) que lleva dos años en una villa cercana a Santiago. Como otros muchos se han venido pensando que iban a encontrar trabajo pronto y que iría mejor que allá. Su médica de cabecera ha puesto en el volante de interconsulta: "síntomas ansiosos por problemas personales. Rechaza ayuda farmacológica y solicita psicoterapia". Tiene un hijo adolescente con relativo fracaso escolar. Nos va diciendo:

"Mi moral está por el piso...Acá no hablan. No saben relacionarse. Ni tan siquiera por el telefonillo del portal dicen a qué vienen".- "Solamente en una ocasión a mi hijo en el colegio le han llamado Argentino de Mierda...Lo más curioso es que el que se lo ha dicho era venezolano".

En tantos años hemos tenido que aprender nuevas metáforas. Al principio describían la angustia diciendo "estoy como dos en un zapato". Para referirse a las rumiaciones obsesivas decían: "la cabeza siempre remoliendo" (metáfora tomada del molino). Pronto pasaron a decir: "mi cabeza no para, siempre centrifugando" (metáfora tomada de las lavadoras).

No nos queda espacio para extendernos en la función de las metáforas y en la necesidad clínica de su manejo.

El poder de la metáfora, cuando viene de dentro del ser humano al atender cualquier asunto importante para él, la hace mil veces más poderosa que cuando es sugerida desde fuera. La medicina actual ha alcanzado un extraordinario desarrollo científico-técnico y se encuentra en el umbral de una potencial revolución a través de la confluencia de la genética-manipulación celular, la nanotecnología, los biosensores y la informática. No ha sido similar el desarrollo de la relación médico-paciente, y una de las mayores críticas a la práctica actual es un pobre "humanismo".

Termino con un esquema, diapositiva, que me ha sido útil en muchas ocasiones para explicar el tema de los atractores, narrativas, diagnóstico popular, etc. 


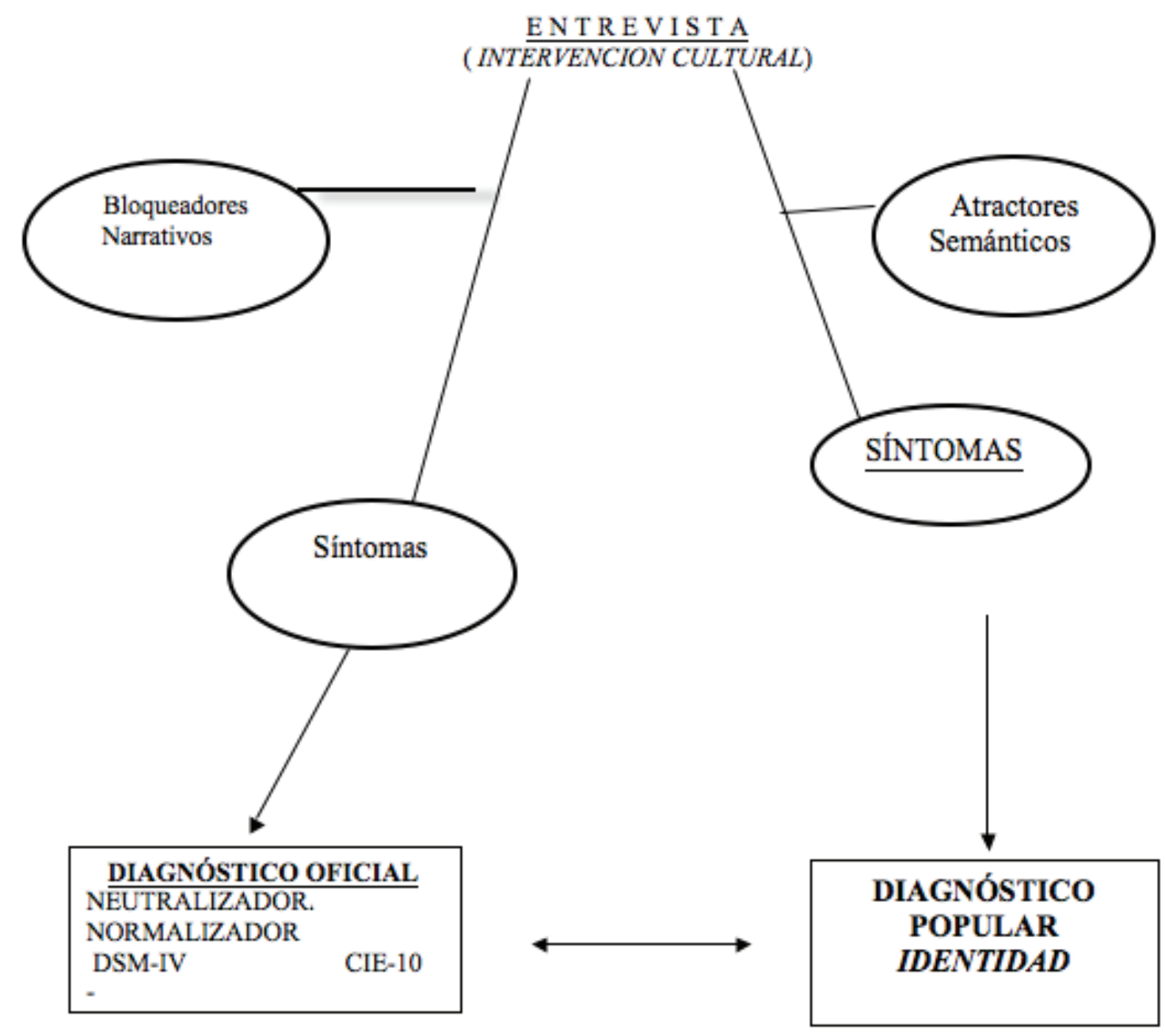

\section{REFERENCIAS BIBLIOGRÁFICAS}

Barthe, Jean-Francois (1990) «Connaissance profane des syntomes e recours thérapeutique ». Revue Française de Sociologie, XXXI, 2.

Foucault, Michel (1997) Il faut défendre la societé. Paris: Gallimard-Seuil.

Kirmayer, Laurence J. (2001) "Cultural Variations in the Clinical Presentation of Depression and Anxiety: Implications for Diagnosis and Treatment". Journal of Clinical Psychiatry, 62 (suppl.13), pp. 22-28.

Pierce, C.A. (1986) Solomon Carter Fuller Lecture. American Psychiatric Association. Annual Meeting, May 1986.

Tizón, Jorge L. (2013) “Racionalización del gasto en salud mental”. Revista de la Asociación Española de Neuropsiquiatría, 113.

Van Os, J.; Hanssen, M.; Bak, M.; Bijl, R.V. y Volleberg, W. (2003) “Do Urbanicity and Familial Liability Coparticipate in Causing Psychosis?". American Journal of Psychiatry, 160,3, pp. 477-482.

Zola, Irving K. (1981) “Culte de la Santé et méfaits de la médicalisation ». Medicine et Societé, 80, pp. 31-51. 